\title{
Investigation of hydraulics transport time scales within the Arvand River estuary, Iran
}

\author{
Amir Etemad-shahidi ${ }^{*}$, Mostafa Pirnia $^{2}$,Hengameh Moshfeghi ${ }^{2}$ \\ and Charles Lemckert ${ }^{1}$ \\ ${ }^{* 1}$ Griffith School of Engineering, Gold Coast campus, Griffith University, QLD, 4222; Email: \\ a.etemadshahidi@griffith.edu.au \\ ${ }^{2}$ School of Civil Engineering, Iran University of Science and Technology, P.O. Box 16765-163, \\ Narmak, Tehran, Iran
}

\begin{abstract}
Transport time scales are key parameters for understanding the hydrodynamic and biochemical processes within estuaries. In this study, the flushing and residence times within the Arvand River estuary have been estimated using a 2D hydrodynamic model called CE-QUAL-W2. The model has been calibrated and verified by two different sets of field data and using the k- $\varepsilon$ vertical eddy diffusivity scheme. Flushing time has been estimated using different methods such as the tidal prism and fraction of freshwater methods. Moreover, residence times have been investigated using pulse residence time (PRT), estuarine residence time (ERT), and remnant function approaches. The results have shown that different methods yield different time scales and freshwater inflow has the greatest impact upon estimation of residence time, while tidal circulation hardly contributes to residence time at all. It has also been shown that the neap-spring
\end{abstract}


circulation and start phase of simulations have negligible effects on the Arvand's time scales. The investigation of bathymetry showed that two sills of the estuary tend to significantly increase residence time. Understanding the applicability of these time scales and their estimation approaches help us to evaluate the water quality management of estuaries.

KEY WORDS: Hydrodynamic modeling; Transport time scale; Flushing time; Residence time; Arvand River estuary

\section{Introduction}

Transport processes within natural water bodies are complicated and difficult to quantify. These processes affect the biochemical reactions of the life in the water, and hydraulic timescales are one of the most useful tools for understanding the behavior of complex aquatic systems. Different types of time scales, such as retention time (Josefson and Rasmussen, 2000); flushing time (Ji et al., 2007); transit time; residence time (Gómez-Gesteira et al., 2003, Kenov et al., 2012); turnover time (Takeoka, 1984); water renewal time (Ribbe et al., 2008); and age (Shen and Lin, 2006) have been used. Various calculation approaches for these time scales rely on their distinctive underlying assumptions. In a comprehensive study, Monsen et al. (2002) distinguished flushing time, residence time and age as three fundamentally different kinds of time scales, and discussed the hypothesis of the approaches used for estimation of time scales within natural systems.

Numerical models are usually used to estimate time scales (e.g. Arega et al. 2008; Barcena et al., 2012; Camacho and Martin, 2013; Choi and Lee 2004; de Brye et al. 2012; Huang et al. 2010; 
Liu et al. 2008; Liu et al. 2011, Manoj, 2012; Wang et al. 2004). Time scales have been used to explain the cause of sedimentation in the system (Mercier and Delhez, 2007); eutrophication (Lehrter, 2008); transport of dissolved substances (Agedah et al., 2009); and phytoplankton growth rate (Wang et al., 2004). Ferreira (2000) used residence time and flushing time to develop a grading procedure for estuaries to evaluate vulnerability and the system's physical capacity of to react to changes. Taljaard et al. (2009) introduced a model to describe the nutrient dynamics within macrotidal estuaries using flushing time and its influence on the stratification and salinity intrusion of the estuaries. Boynton et al. (1995) showed that residence time is a significant parameter in Chesapeake Bay, and should be used as the basis for comparative analysis of the ecosystem-scale nutrient budget. In another study, Uncles et al. (2002) illustrated the importance of residence time as an influential factor on the distributions of suspended and dissolved materials within estuaries. Mercier and Delhez (2007) used an estimated age map from the coast of Belgium to diagnose the sedimentation process. Hasanloo and Etemad-Shahidi (2011) also investigated the relationship between the thermal stratification and hydraulic time scales in Dez reservoir in Iran.

Different approaches have been used to estimate these time scales, particularly the flushing time, which is a bulk first-order time scale that describes the general exchange characteristics of a water body without identifying the underlying physical processes, the relative importance of those processes, or their spatial distribution (Monsen et al., 2002). Conversely, Dyer (1973) defined this time scale as time needed to replace the water within a system with fresh water from the outside. This time scale has been estimated variously as a fraction of freshwater (Dyer, 1973, Sheldon and Alber, 2002, Wang et al., 2004, Huang, 2007); volume divided by inflow rate 
(Dyer, 1973, Ferreira, 2000); and tidal prism (Luketina, 1998, Wang et al., 2004, Ji et al., 2007) approaches.

Unlike the flushing time, residence time is a local time scale that should be calculated for a specific location. The time that a mass of tracer will remain within the system is called residence time (Zimmerman, 1976). Residence time also has different forms of calculation, such as pulse residence time (Miller and McPherson, 1991, Sheldon and Alber, 2002, Abdelrhman, 2005, Huang and Liu, 2009); estuarine residence time (Miller and McPherson, 1991, Chen, 2007); and using remnant function integration (Takeoka, 1984, Huang and Liu, 2009).

While the above time scales have been calculated and used to explain the biochemical and hydrological processes of different types of water bodies, a single time scale cannot explain the system completely (Hasanloo and Etemad-Shahidi, 2011). The approach used to calculate these scales should be chosen very carefully and should consider the assumption of the approach, the hydrodynamics of the system and the kind of problem that has been dealt with. Noting the importance of the Arvand River as a source of freshwater, the focus of previous hydrodynamics and water quality studies in this area was mainly on the salinity intrusion length and obtaining a predictive formula for it (Zahed et al., 2008; Etemad-Shahidi et al., 2011). In this article, different approaches suggested for estimating the hydraulic time scales have been compared with each other, using a numerical model. The results have been analyzed and the relative importance of three major physical transport mechanisms (i.e. freshwater inflow, tidal circulation and density-induced circulation) has been investigated. This investigation is of vital importance for understanding the involved processes and dynamics of transport mechanisms in this water body. 
In addition, the effects of bathymetric features on the residence time of the estuary was explored and simple semi-empirical formulas were given for different hydraulic time scales as rapid assessment tools for water quality managerial purposes. Finally, the effects of tidal characteristics on residence time and flushing time have been discussed.

\section{Study Area}

Arvand is a narrow estuary in south-west of Iran that forms a portion of the border between Iran and Iraq (Figure 1). Arvand is formed by the conjunction of the Tigris and Euphrates rivers in Iraq and Karun River in Iran. Three major cities: Abadan, Khoramshahr and Basra, are located around it, with the river running mostly toward the south to reach the Persian Gulf. The estuary's vertical salinity structure varies from nearly homogenous in the dry season to strongly stratified during wet seasons (Zahed et al., 2008). The maximum tidal range of the Arvand estuary is about $6 \mathrm{~m}$, with an average of $3 \mathrm{~m}$, and the average annual discharge is 1040 cubic meters per second. The salinity intrusion within this estuary has been studied by Zahed et al. (2008), and the numerical results have recently been compared with those of semi-empirical equations of salinity intrusion by Etemad-Shahidi et al. (2011).

\section{Model description}

CE-QUAL-W2, a two dimensional laterally-averaged hydrodynamic and water quality model that has already been successfully used to simulate different stratified water bodies around the world (e.g. Bowen 2000, Etemad-Shahidi et al. 2009), was selected for modeling the Arvand 
River. One of the advantages of CE-QUAL-W2 is that the time step is calculated automatically in the model using the following criteria (Cole and Wells, 2006):

$$
\Delta t \leq \frac{1}{2\left[\frac{A x}{\Delta x^{2}}+\frac{A z}{\Delta z^{2}}\right]+\frac{Q}{V}+\frac{\sqrt{\frac{\Delta \rho}{\rho} \frac{g H}{2}}}{\Delta x}}
$$

where, $\Delta t$ is the time step, $A x$ is the horizontal eddy diffusivity, $A z$ is the vertical eddy diffusivity, $\Delta x$ is the cell length, $\Delta z$ is the cell thickness, $Q$ is the cell total discharge, $V$ is the cell volume and $\Delta \rho$ is the density difference.

The model uses a finite difference implicit/explicit formulation to solve the system's hydrodynamics. The governing formulations have been discussed in detail by Cole and Wells (2006). This study has used Version 3.5 of CE-QUAL-W2, which has a set of vertical eddy

diffusivity schemes such as RNG (Simoes, 1998), W2N (Rodi, 1993, Cole and Buchak, 1995) and k- $\varepsilon$ module (Cole and Wells, 2006).

\section{Calibration and verification}

The CE-QUAL-W2 model has simulated the Arvand River using measured water elevation and salinity profiles. A set of water elevation data at Abadan (upstream) and Persian Gulf (downstream) stations have been used to calibrate the model and determine the Manning Coefficient. Different Manning coefficients have been evaluated using mean absolute error (Equation 2): 


$$
A M E=\frac{1}{m} \sum_{i=1}^{m}\left(\left|X_{i}-Y_{i}\right|\right)
$$

where $m$ is the number of data points; $X_{i}$ is the predicted value; and $Y_{i}$ is the measured value. The vertical thickness of all layers in the model was $1 \mathrm{~m}$, and the domain has been divided into 43 segments. The selected Manning coefficient $(n=0.022)$ had an absolute mean error of less than $0.054 \mathrm{~m}$ for the observed elevation at Khosrowabad station (Figure 1). Figure 2 shows the agreement of simulated levels and the field data.

Using different vertical eddy diffusivity schemes had a marginal effect on water levels. Calibrating the model for the horizontal eddy diffusivity and selecting the best vertical eddy diffusivity scheme were completed using measured salinity profiles. Table 1 shows that k- $\varepsilon$ outperforms the W2N and RNG closure schemes. The agreement of measured and simulated salinity profiles at Ghosbeh station is illustrated in Figure 3. Zahed et al. (2008) used W2N, Nick and RNG scheme and showed that RNG scheme slightly overestimated the vertical stratification, and stated that $\mathrm{W} 2 \mathrm{~N}$ is a more reliable algorithm for the Arvand River. Table 1 indicates that k- $\varepsilon$ scheme is an even better scheme. In this table, the root mean square error (RMSE) and scatter index are calculated as follows:

$$
\begin{aligned}
& R M S E=\sqrt{\frac{1}{m} \sum_{i=1}^{m}\left(X_{i}-Y_{i}\right)^{2}} \\
& S I=\frac{1}{\bar{Y}} \sqrt{\frac{1}{m} \sum\left(X_{i}-Y_{i}\right)^{2}}
\end{aligned}
$$


where overbars denote the average of the measured values.

The verification of the model is presented in Figure 4 and shows the k- $\varepsilon$ module is the most accurate scheme, and RNG has overestimated the stratification structure. This is in line with recent findings about the performance of different closure schemes (Zahed et al., 2008, EtemadShahidi et al., 2008). The results obtained by k- $\varepsilon$ scheme in Figure 4 - showing an $R M S E$ of $0.126 \mathrm{~m}$ and absolute mean error of $0.327 \mathrm{~m}$ - is acceptable, considering inevitable errors of the modeling and measurements.

\section{Time scales}

In order to estimate the time scales, the verified model was executed using a constant freshwater inflow rate at the upstream boundary and at tidal level in the Persian Gulf. The lowest average discharge of the estuary is $240 \mathrm{~m}^{3} / \mathrm{s}$ and the annual mean discharge is about $1040 \mathrm{~m}^{3} / \mathrm{s}$. Therefore, six different inflow rates within this range were used for each approach. with the downstream boundary condition being generated using harmonic tide table constituents $\left(\mathrm{M}_{2}, \mathrm{~S}_{2}\right.$, $\mathrm{K}_{1}$ and $\mathrm{O}_{1}$ ). The tidal constituents were used to generate long term downstream boundary conditions for the used different inflow rates. This was because of that tidal measurements showed that more than ninety per cent of tidal variations in the area were due to these components. To investigate the importance of tidal amplitude, each inflow rate was simulated four times, with the starting time of each simulation being lagged $0,3.5,7.0,10.5$ and 14 days. Consequently, these four tests complete the 14-day period of transition from the neap to the spring tides. 


\section{Flushing time}

The simplest flushing time scale within an aquatic system is the proportion of the volume of water to the inflow rate. Geyer et al. (2000) defined flushing time as the ratio of the mass of a scalar within a reservoir to the rate of renewal of the scalar:

$$
T_{f}=M / M^{\circ}
$$

where $M$ is the measured scalar, and $M^{\circ}$ is the renewal rate of $M$. If the scalar is assumed to be the volume of the system $(V)$, its renewal rate would be inflow rate $(Q)$, as has been shown in Equation 6.

$$
T_{f}=V / Q
$$

where $V$ is the system volume and $Q$ is the system's net inflow. Flushing time could also be defined as the ratio of mass of a tracer within the system to its inflow flux. Within a steady, onedimensional advective system, the result of these two equations would be the same. However, natural estuaries are unsteady most of the time, and the volume of a large natural water body or the mass of the tracer within it is often unknown (Monsen et al., 2002). Thus the average volume of the system and the tracer mass were calculated using the verified model in this study.

In practice, Equation 5 is used for a constant injection of a material into the system by a point source such as a sewage outlet. In this situation, a sewage pipe outlet acts like a steady point 
source, and the flushing time is the average time needed for the pollution to leave the system after cutting the source. The estimation of flushing time using Equation 5 requires the estimation of the tracer's mass and its inflow rate. Therefore, in this numerical study a conservative tracer was released into the system as a continuous point source with a certain concentration. The mass of the tracer was monitored for a year-long period, and the inflow of freshwater was set to one gram of tracer per cubic meter; thus, the flux of mass was known. This approach indicates that the change in mass flux should not be an issue in calculation of the flushing time. The results have shown that the mass flux variations cause less than one per cent change in flushing time calculations. Figure 5 shows the system reaches a quasi-steady state after some time, but due to the unsteady nature of the estuary, the mass content oscillates. To calculate the flushing time it was assumed that the system reaches equilibrium after 100 days, and the average, maximum and minimum quantities of the tracer's mass were also obtained for another 100-day period.

Figure 6 shows the estimated flushing times derived using Equations 5 and 6, and the system's average volume (as estimated by the model). The given bands are due to the unsteady nature of the outgoing mass flux. During the ebb tide the outgoing flux increases, so the tracer leaves the system; while during flood tides the outgoing flux decreases, so the mass of tracer within the domain increases. Hence, the tracer's mass fluctuates daily, as does the flushing time. The difference between the two methods shows that Equation 5 overestimated the flushing time. Because of the steady nature of Equation 4, it is assumed that after reaching equilibrium, inflow and outflow mass fluxes are equal. However, in reality, due to the dispersion of the tracer and after stopping the mass influx and cutting the source, the outgoing flux gradually decreases to zero, although the outflow remains constant. Thus Equation 5 overestimates flushing time. On 
the other hand, the freshwater inflow containing the tracer does not mix completely with the bottom salty water. Therefore, the bottom saline layers of the estuary are almost tracer-free, while the top layers store an infinite amount of tracer. Hence the bottom layers do not engage in the flushing time estimation using Equation 5. In Equation 6, the total volume of the estuary is considered, and thus the fraction's numerator becomes larger, and the obtained time scales are overestimated. When inflow increases, the saline water is pushed further back to the sea and a larger volume of freshwater is available for the tracer to dissolve into. Consequently, the results of Equations 5 and 6 become closer during wet seasons.

The tidal prism method is another way of calculating the flushing time of a system that is subject to tidal circulation. This approach is applicable to a well-mixed system when only the tidal range and system geometry is known (Monsen et al. 2002). With this method, the river inflow should be very small compared with the tidal flow. Equation 7 shows the estimation of flushing time using tidal prism method:

$$
T_{f}=V_{s} T / P
$$

where $P$ is the volume between high and low tide; $T$ is the tidal period; and $V_{s}$ is the mean volume of the system (Monsen et al., 2002) or the maximum volume the estuary (Dyer, 1973). Estimation of flushing time using the tidal prism approach and mean system volume showed the system's flushing time is about three days; which is relatively low due to ignorance of role of river discharge in the transport process. The volumes obtained from the model using different inflow rates were nearly the same; hence the tidal prism approach yields only one flushing time 
for any inflow rate, and is much lower than those obtained by other methods. This underestimation is chiefly due to the fact the system is driven by freshwater inflow and not well mixed; this has been observed in other studies as well (Monsen et al., 2002, Wang et al., 2004).

The fraction of freshwater method $(F F M)$ is also a commonly-used procedure for estimating flushing time within estuaries, and with this approach, it is assumed the system is steady. The FFM is defined by Dyer (1973) as follows:

$$
\begin{gathered}
T_{f}=\sum_{i=1}^{k} f_{i} \cdot V_{i} / Q \\
f=\frac{S_{s}-S_{k}}{S_{s}}
\end{gathered}
$$

In these equations, $S_{s}$ is the salinity of seawater, and $S_{k}$ is the average salinity of the selected portion of the estuary. Obviously, since $f \leq 1$, this method would estimate a lower flushing time compared with that of Equation 6. The results of the model were used for the calculation of average salinities of the Arvand River for a 50-day period (Figure 7). The results of the FFM approach are given in Figure 8. In previous studies, power equations (Huang, 2007) or exponential equations (Huang and Spaulding, 2002, Wang et al., 2004) have been used to describe the relationship between the freshwater inflow and fraction of freshwater flushing time. Arvand's flushing time using this approach is best described by the following equation:

$$
T_{f}=1311 \times Q^{-0.825}
$$


This equation shows a power for $Q$ that is close to -1 ; this power shows that the fraction of freshwater method yields a close approximation to Equation 4.

\section{Residence time}

Residence time has often been confused with flushing time, but while residence time is calculated using a local time scale, flushing time is usually calculated for an entire system. Different approaches, such as Pulse Residence Time (PRT), Estuarine Residence Time (ERT), and Remnant Function Integration (Takeoka, 1984, Miller and McPherson, 1991), have been introduced for calculation of residence time.

$P R T$ is the time a pulse tracer requires for most of it $(67 \%, 90 \%, 95 \%$ or $100 \%)$ to leave the domain (Miller and McPherson, 1991). In practice, $P R T$ is used to determine how much a pollutant entering a system within a short period of time, resides in that system. In order to estimate $P R T$, a conservative tracer with arbitrary concentration was released into the most upstream segment of the model. The time needed for 95 per cent of the tracer's mass to reach the outlet and leave the system was assumed to be PRT. Figure 9 shows the estimated $P R T$ 's in spring and neap conditions. It was found that for different tidal amplitudes (neap and spring) the changes of the $P R T$ were less than 7\%. This figure also shows that tidal range is unimportant during wet seasons with high inflow rates. Equation 11 gives a power formulation for rapid estimation of $P R T$ with $\mathrm{R}^{2}=0.9997$ :

$$
T_{R}=3314.5 Q^{-0.907}
$$


Similar to the flushing time estimated using $F F M$, the power of $Q$ in Equation 11 is close to -1 . Thus, the residence time using this method could be approximated by Equation 6 . This equation shows the residence time is governed by the freshwater flow, and is inversely related to the river discharge. This is in line with the findings of Kenov et al. (2012) within Mondego estuary.

The relative effects of three major physical forcings, i.e., freshwater inflow, tidal circulation and density-induced circulation on the PRT were also investigated. The residence times and flushing rates estimated in the base scenario (Table 2), show the cumulative effect of all three forcings. In order to quantify the effects of density-induced circulation, a second scenario assuming a constant density (salinity) along the estuary was run and PRT's values were recalculated. Then, the relative contribution of density-induced circulation was estimated by calculating the relative difference between the results obtained from the base scenario and those of second scenario (Table 2). Table 2 shows that increasing the inflow rate causes the relative importance of density circulation to decrease. This is because the saline water is pushed towards the sea at high flow rates and more space is free for freshwater to flush the tracer mass.

In the second scenario (constant salinity), the flushing rate obtained for the case with zero inflow (0.0009 $\left.\mathrm{Day}^{-1}\right)$ shows the role of tidal circulation in the transport. Therefore, the relative contribution of tide at different inflow conditions were calculated based on the ratio between this rate and the flushing rates obtained in the base scenario. Finally, the relative contribution of 
inflow was calculated by subtracting the relative contributions of density-induced and tidal circulations from unity. Results imply that the role of tide in the transport mechanism is marginal in this estuary and its relative contribution is mostly less than $2 \%$. On the other hand, the river discharge has the most important role in the transport of matters in this estuary with an average contribution of about $80 \%$.

To calculate $E R T$, a conservative tracer was firstly distributed uniformly in the model. Then the time needed for $95 \%$ of the tracer to leave the system was considered as ERT. Figure 10 shows the results of the ERT estimation for different inflow rates. As seen in this figure, the residence time decreases rapidly by increasing the inflow rates. Equation 12 introduces a power formulation for rapid estimation of $E R T$ with $\mathrm{R}^{2}=0.9991$ :

$$
T_{R}=1446.3 Q^{-0.822}
$$

This equation is similar to that of the fraction of freshwater flushing time. This approach of residence time estimation is useful when the estuary has been exposed to a large source of pollution for a long time. In this case, all of the water would be affected by the pollution, so the time needed for the pollution to leave the estuary would be close to the flushing time definition.

The residence time estimation approach suggested by Zimmerman (1976) indicates that if the primary mass of the tracer within the system is $M_{0}$ and the tracer mass over time is $M(t)$ function, the residence time of tracer would be: 


$$
T_{R}=\frac{1}{M_{0}} \int_{0}^{\infty}-t\left(\frac{d M(t)}{d t}\right) d t
$$

Takeoka (1984) pointed out that by using integration by parts, the formulation would be in the following form:

$$
T_{R}=\int_{0}^{\infty} \frac{d M(t)}{M_{0}} d t=\int_{0}^{\infty} r(t) d t
$$

The $r(t)$ is called remnant function. In this approach of residence time estimation, the area under the mass-time curve needs to be calculated. Residence time was calculated for six different inflow rates and 43 release points (Figure 11). This figure shows that, expectedly, increasing the inflow causes a decrease in the residence time. Further, as the tracer release point moves towards the upstream, residence time increases. When the release point moves further up, the length of the estuary the tracer should travel increases. Thus, assuming a constant velocity of a water parcel, the time the tracer takes to reach the outlet increases, as does the residence time. Figure 11 also shows that residence time increases unexpectedly in the segment 67 kilometers from the mouth of the river. Station BT1, which is relatively deep and narrow, is located behind a sill within this segment (Figure 7). A portion of tracer released in this section can become trapped, which can cause an increase in residence time estimation. BT4 is located at a distance of 26 kilometers from the mouth of the river. Similarly, the sill placed at this location and the neighboring narrow depression cause the residence time to increase at a distance of $27 \mathrm{~km}$ because of the tracer being trapped at this station. This indicates that bathymetry does effect 
residence time and consequently, accurate bathymetric data is required when conducting such studies.

The start phase of simulation sometimes affects the calculation of residence time. Arega and Badr (2010) have reported the Lagrangian method is highly sensitive to the change of simulation start time, while an Eulerian method does not show that kind of behavior. To test the influence of tidal phase on this time scale, six extreme tidal phases were selected. The first four phases were slack water, low slack water, high water and low water. In addition, two other phases at mean sea level time, which have maximum tidal velocity, were selected. Simulated residence time for the release point at $74 \mathrm{~km}$ and a $580 \mathrm{~cm}$ inflow rate showed less than $2 \%$ variation (Table 3 ). Because of the Eulerian method and a fairly long residence time (of about eight days), the effect of phase change of simulation is negligible using this method. However, as the release point moves along the estuary to the river mouth, the residence time becomes more sensitive to the release time (phase) - up to $20 \%$. Moving the tracer's release point along the river toward the sea yields a shorter residence time; shorter residence times are more sensitive within a tidal cycle. The ebb time within a tidal cycle, has a stronger impact upon flushing in the estuary than does the tide. Thus, when the residence time of a release point is shorter than one day, most of it would be flushed in the ebb, so the phase changing of the simulation could cause a significant change in the residence time. Longer residence time means more tidal cycles, which leads to less importance of release time (phase).

\section{Summary and conclusion}


In this study, various time scales of the Arvand River were investigated. First a $2 \mathrm{D}$ numerical model, which had been calibrated and verified using field data, was applied to the estuary. It was then used to estimate three major time scales: flushing time, residence time, and age. The results showed variations of tide amplitude have minimal influence on flushing time. Furthermore, changing the phase of the simulation start point has a negligible effect on the residence time. Freshwater inflow was found to be the most important factor in residence time variation, with about $80 \%$ contribution to the renewing the water within the domain. Density-induced circulation was the second most important factor, while tidal circulation has hardly any effect on the hydraulic time scales. It was shown that ERT approach for estimation of residence time is useful when the estuary has been exposed to a large source of pollution for a long time.

\section{Acknowledgment}

We are thankful to the KWPO and Ministry of Power for the calibration data. We are also grateful to Professor Scott Wells for providing the CE-QUAL-W2 model. 


\section{References}

Abdelrhman MA. 2005. Simplified modeling of flushing and residence times in 42 embayments in New England, USA, with special attention to Greenwich Bay, Rhode Island. Estuarine, Coastal and Shelf Science 62 : 339-351.

Agedah EC, Binalaiyifa HE, Ball AS, Nedwell DB. 2009. Sources, turnover and bioavailability of dissolved organic nitrogen (DON) in the Colne estuary, UK. Marine Ecology Progress Series 382 : 23-33.

Arega F, Armstrong S, Badr AW. 2008. Modeling of residence time in the East Scott Creek Estuary, South Carolina, USA. Journal of Hydro-Environment Research 2 : 99-108.

Barcena, J. E., Garcia, A. Gomez, A. 2012 .Spatial and temporal flushing time approach in estuaries influenced by river and tide. An application in Suances Estuary (Northern Spain). Estuarine, Coastal and Shelf Science 112 : 40-51,2012

Bowen JD. 2000. Calibration performance of a two-dimensional, laterally-averaged eutrophication model of a partially mixed estuary. Proceedings of the International Conference on Estuarine and Coastal Modeling: 1244-1258.

Boynton, W. Garber, J. Summers, R. 1995. Inputs, transformations and transport of nitrogen and phosphorous in Chesapeake bay and selected tributaries. Estuaries 18: 285-314

Camacho, R. A.; Martin, J. L. 2013. Hydrodynamic Modeling of First-Order Transport Timescales in the St. Louis Bay Estuary, Mississippi_Journal of Environmental EngineeringASCE 139: 317-331

Chen X. 2007. A laterally averaged two-dimensional trajectory model for estimating transport time scales in the Alafia River estuary, Florida. Estuarine, Coastal and Shelf Science 75 : 358370 .

Choi, K. W. Lee, J. H. W. 2004. Numerical determination of flushing time for stratified water bodies. Journal of Marine Systems 50: 263-281.

Cole T, Buchak E. 1995. CE-QUAL-W2: A Two-Dimensional, Laterally Averaged, Hydrodynamic and Water Quality Model, Version 2.0, Technical Report El-95-1. U.S. Army Engineer Waterways Experiment Station.

Cole TM, Wells SA. 2006. CE-QUAL-W2: A two-dimensional, laterally averaged, Hydrodynamic and Water Quality Model, Version 3.5. Instruction Report EL-06-1

Vicksburg, MS, US Army Engineering and Research Development Center.

De Brye, B., de Brauwere, A., Gourge, O., Delhez, E. J. M., Deleersnijder, E. 2012. Water renewal timescales in the Sheldt Estuary. Journal of Marine Systems 94: 74-86. 
Deleersnijder É, Campin JM, Delhez EJM. 2001. the concept of age in marinemodeling i. theory and preliminary model results. Journal of Marine Systems 28, 229-267

Dyer KR. 1973. Estuaries A Physical Introduction, New York, John wiley \& sons.

Etemad-Shahidi, A, Dorostkar A, Liu W C. 2008. Prediction of Salinity Intrusion in Danshuei Estuarine System. Hydrology Research 38 : 497-505

Etemad-Shahidi, A., Imberger, J 2002. Anatomy of turbulence in a narrow and strongly stratified estuary. Journal of Geophysiocal Research-Ocean $107: 3070$

Etemad-Shahidi, A., Afshar, A., Alikia, H., Moshfeghi, H. 2009. Total Dissolved Solid Modeling; Karkheh Reservoir Case Example. International Journal of Environmental Research 3 : 671-680

Ferreira JG. 2000. Development of an estuarine quality index based on key physical and biogeochemical features. Ocean \& Coastal Management 43 : 99-122.

Geyer WR, Morris JT, Pahl FG, Jay DA. 2000. Interaction between physical processes and ecosystem structure: A comparative approach. Island Press.

Gómez-Gesteira M, deCastro M, Prego R. 2003. Dependence of the water residence time in Ria of Pontevedra (NW Spain) on the seawater inflow and the river discharge. Estuarine, Coastal and Shelf Science $\mathbf{5 8}:$ 567-573.

Hasanloo D, Etemad-Shahidi A. 2011. On the estimation of transport timescales - Case study: The Dez reservoir. Journal of Hydroinformatics 13 : 217-228.

Huang W. 2007. Hydrodynamic modeling of flushing time in a small estuary of North Bay, Florida, USA. Estuarine, Coastal and Shelf Science 74 : 722-731.

Huang W, Liu X. 2009. Effects of reducing river flow on pulse residence time in Little Manatee River, USA. Transactions of Tianjin University 15 : 95-100. DOI: 10.1007/s12209-009-0017-2.

Huang, W., Liu, X., Chen, X., Flannery, M. 2010. Estimating river flow effects on water ages by hydrodynamic modeling in Little Manatee River estuary, Florida, USA. Environmental Fluid Mechanics, 10: 197-211.

Huang W, Spaulding M. 2002. Modelling residence-time response to freshwater input in Apalachicola Bay, Florida, USA. Hydrological Processes 16: 3051-3064. DOI: 10.1002/hyp.1088.

Ji Z-G, Hu G, Shen J, Wan Y. 2007. Three-dimensional modeling of hydrodynamic processes in the St. Lucie Estuary. Estuarine, Coastal and Shelf Science 73: 188-200. 
Josefson AB, Rasmussen B. 2000. Nutrient Retention by Benthic Macrofaunal Biomass of Danish Estuaries: Importance of Nutrient Load and Residence Time. Estuarine, Coastal and Shelf Science 50: 205-216.

Kenov A I, Garcia A C, Neves R. 2012 . Residence time of water in the Mondego estuary (Portugal). Estuarine, Coastal and Shelf Science 106 : 13-22.

Lehrter JC. 2008. Regulation of eutrophication susceptibility in oligohaline regions of a northern Gulf of Mexico estuary, Mobile Bay, Alabama. Marine Pollution Bulletin 56: 1446-1460.

Liu, W. C., Chen, W. B., Kuo, J. T. Wu, C. 2008. Numerical determination of residence time and age in a partially mixed estuary using three-dimensional hydrodynamic model. Continental Shelf Research 28: 1068-1088.

Liu, W. C., Chen, W. B., Hsu, M. H. 2011. Using a three dimensional particle-tracking model to estimate the residence time and age of water in a tidal estuary. Computer Geoscience, 37: 11481161.

Luketina D. 1998. Simple tidal prism models revisited. Estuarine, Coastal and Shelf Science 46: 77-84.

Manoj, N. T. 2012. Estimation of flushing time in a monsoonal estuary using observational and numerical approaches. Natural Hazards 64: 1323-1339

Mercier C, Delhez EJM. 2007. Diagnosis of the sediment transport in the Belgian Coastal Zone. Estuarine, Coastal and Shelf Science 74: 678-691.

Miller RL, McPherson BF. 1991. Estimating estuarine flushing and residence times in Charlotte Harbor, Florida, via salt balance and a box model. Limnology \& Oceanography 36: 602-612.

Monsen NE, Cloern JE, Lucas LV, Monismith SG. 2002. A comment on the use of flushing time, residence time, and age as transport time scales. Limnology and Oceanography 47: 15451553.

Ribbe J, Wolff J-O, Staneva J, Gräwe U. 2008. Assessing water renewal time scales for marine environments from three-dimensional modelling: A case study for Hervey Bay, Australia. Environmental Modelling \& Software 23: 1217-1228.

Rodi W. 1993. Turbulence Models and Their Application in Hydraulics. IAHR, A.A. Balkema, Rotterdam, the Netherlands.

Sheldon J, Alber M. 2002. A comparison of residence time calculations using simple compartment models of the Altamaha River estuary, Georgia. Estuaries and Coasts 25: 13041317. DOI: $10.1007 / \mathrm{bf02692226.}$

Shen J, Lin J. 2006. Modeling study of the influences of tide and stratification on age of water in the tidal James River. Estuarine, Coastal and Shelf Science, 68: 101-112. 
Simoes F. 1998. An Eddy Viscosity Model for Shallow-Water Flows. Water Resources Engineering 98: 1858-1863.

Takeoka H. 1984. Fundamental concepts of exchange and transport time scales in a coastal sea. Continental Shelf Research 3: 311-326.

Taljaard S, van Niekerk L, Joubert W. 2009. Extension of a qualitative model on nutrient cycling and transformation to include microtidal estuaries on wave-dominated coasts: Southern hemisphere perspective. Estuarine, Coastal and Shelf Science 85: 407-421.

Uncles RJ, Stephens JA, Smith RE. 2002. The dependence of estuarine turbidity on tidal intrusion length, tidal range and residence time. Continental Shelf Research 22: 1835-1856.

Wang C-F, Hsu M-H, Kuo AY. 2004. Residence time of the Danshuei River estuary, Taiwan. Estuarine, Coastal and Shelf Science 60: 381-393.

Zahed F, Etemad-Shahidi A, Jabbari E. 2008. Modeling of salinity intrusion under different hydrological conditions in the Arvand River Estuary. Canadian Journal of Civil Engineering 35: 1476-1480.

Zimmerman JTF. 1976. Mixing and flushing of tidal embayments in the western Dutch Wadden Sea part I: Distribution of salinity and calculation of mixing time scales. Netherlands Journal of Sea Research 10: 149-191. 
Table 1. Error measures of salinity modeling for Ghosbeh station at 20:00 of 6 February

\begin{tabular}{cccc} 
& $K-\varepsilon$ & $W 2 N$ & $R N G$ \\
\hline AME (ppt) & 0.95 & 2.88 & 3.40 \\
RMSE (ppt) & 1.34 & 9.98 & 19.34 \\
SI & 0.07 & 0.52 & 1.00 \\
\hline
\end{tabular}


Table 2. Relative contribution of three major physical transport mechanisms on the $P R T$

\begin{tabular}{|c|c|c|c|c|c|c|c|}
\hline Inflow $\left(\mathrm{m}^{3} / \mathrm{s}\right)$ & 0 & 240 & 320 & 430 & 580 & 780 & 1040 \\
\hline Base scenario- $P R T$ (Day) & 778 & 23.16 & 17.71 & 13.42 & 10.2 & 7.85 & 6.14 \\
\hline $\begin{array}{c}\text { Second scenario -PRT } \\
\text { (Day) }\end{array}$ & 1168 & 29.46 & 21.86 & 16.31 & 12.19 & 9.1 & 6.89 \\
\hline $\begin{array}{l}\text { Base scenario - Flushing } \\
\quad \text { rate, } P R T^{-1}\left(\mathrm{Day}^{-1}\right)\end{array}$ & 0.0013 & 0.0432 & 0.0565 & 0.0745 & 0.0980 & 0.1274 & 0.1629 \\
\hline $\begin{array}{l}\text { Second scenario- Flushing } \\
\text { rate, } P R T^{-1}\left(\mathrm{Day}^{-1}\right)\end{array}$ & 0.0009 & 0.0339 & 0.0457 & 0.0613 & 0.0820 & 0.1099 & 0.1451 \\
\hline $\begin{array}{l}\text { Density-induced } \\
\text { contribution }\end{array}$ & - & $22 \%$ & $19 \%$ & $18 \%$ & $16 \%$ & $13 \%$ & $11 \%$ \\
\hline $\begin{array}{c}\text { Tidal circulation } \\
\text { contribution }\end{array}$ & - & $2 \%$ & $2 \%$ & $1 \%$ & $0.9 \%$ & $0.7 \%$ & $0.5 \%$ \\
\hline Inflow contribution & - & $76 \%$ & $79 \%$ & $81 \%$ & $83.1 \%$ & $86.3 \%$ & $88.5 \%$ \\
\hline
\end{tabular}


Table. 3 Effects of the start phase on the residence time, $Q=580 \mathrm{~m}^{3} / \mathrm{s}$

\begin{tabular}{|c|c|c|c|c|c|c|c|}
\hline $\begin{array}{c}\text { Release } \\
\text { Segment }\end{array}$ & $\begin{array}{l}\text { Segment } \\
\text { of interest }\end{array}$ & $\begin{array}{c}\text { High } \\
\text { slack } \\
\text { water }\end{array}$ & $\begin{array}{l}\text { Low } \\
\text { slack } \\
\text { water }\end{array}$ & $\begin{array}{c}\text { High } \\
\text { tide }\end{array}$ & $\begin{array}{l}\text { Low } \\
\text { Tide }\end{array}$ & $\begin{array}{c}\text { MSL } \\
\text { (rising) }\end{array}$ & $\begin{array}{c}\text { MSL } \\
\text { (falling) }\end{array}$ \\
\hline 2 & 2 & 0.06 & 0.06 & 0.05 & 0.05 & 0.07 & 0.05 \\
\hline 2 & 3 & 0.20 & 0.21 & 0.17 & 0.20 & 0.21 & 0.17 \\
\hline 2 & 4 & 0.44 & 0.44 & 0.38 & 0.45 & 0.41 & 0.41 \\
\hline 2 & 5 & 0.67 & 0.66 & 0.64 & 0.71 & 0.63 & 0.69 \\
\hline 2 & 6 & 0.98 & 0.99 & 1.00 & 1.04 & 0.98 & 1.04 \\
\hline 2 & 7 & 1.23 & 1.26 & 1.24 & 1.27 & 1.23 & 1.27 \\
\hline 2 & 8 & 1.53 & 1.56 & 1.52 & 1.55 & 1.51 & 1.54 \\
\hline 2 & 9 & 1.78 & 1.79 & 1.74 & 1.79 & 1.73 & 1.77 \\
\hline 2 & 10 & 1.95 & 1.95 & 1.91 & 1.97 & 1.90 & 1.95 \\
\hline 2 & 11 & 2.11 & 2.10 & 2.07 & 2.13 & 2.05 & 2.11 \\
\hline 2 & 12 & 2.31 & 2.32 & 2.30 & 2.34 & 2.27 & 2.34 \\
\hline 2 & 13 & 2.46 & 2.47 & 2.45 & 2.48 & 2.42 & 2.48 \\
\hline 2 & 14 & 2.70 & 2.70 & 2.69 & 2.71 & 2.66 & 2.70 \\
\hline 2 & 15 & 2.91 & 2.90 & 2.88 & 2.91 & 2.87 & 2.90 \\
\hline 2 & 16 & 3.14 & 3.13 & 3.12 & 3.14 & 3.10 & 3.13 \\
\hline 2 & 17 & 3.29 & 3.28 & 3.27 & 3.29 & 3.25 & 3.28 \\
\hline 2 & 18 & 3.44 & 3.43 & 3.42 & 3.44 & 3.40 & 3.43 \\
\hline 2 & 19 & 3.59 & 3.58 & 3.58 & 3.59 & 3.56 & 3.58 \\
\hline 2 & 20 & 3.78 & 3.77 & 3.77 & 3.79 & 3.76 & 3.77 \\
\hline 2 & 21 & 3.98 & 3.98 & 3.97 & 3.99 & 3.96 & 3.98 \\
\hline 2 & 22 & 4.22 & 4.22 & 4.21 & 4.23 & 4.21 & 4.22 \\
\hline 2 & 23 & 4.42 & 4.41 & 4.39 & 4.43 & 4.40 & 4.41 \\
\hline 2 & 24 & 4.58 & 4.58 & 4.55 & 4.59 & 4.56 & 4.57 \\
\hline 2 & 25 & 4.72 & 4.72 & 4.69 & 4.73 & 4.70 & 4.71 \\
\hline 2 & 26 & 4.87 & 4.88 & 4.84 & 4.89 & 4.85 & 4.87 \\
\hline 2 & 27 & 5.04 & 5.05 & 5.02 & 5.06 & 5.03 & 5.04 \\
\hline 2 & 28 & 5.22 & 5.24 & 5.20 & 5.25 & 5.22 & 5.22 \\
\hline 2 & 29 & 5.42 & 5.45 & 5.40 & 5.46 & 5.42 & 5.43 \\
\hline 2 & 30 & 5.59 & 5.62 & 5.57 & 5.63 & 5.59 & 5.60 \\
\hline 2 & 31 & 5.81 & 5.85 & 5.79 & 5.86 & 5.81 & 5.83 \\
\hline 2 & 32 & 6.06 & 6.11 & 6.04 & 6.12 & 6.07 & 6.09 \\
\hline 2 & 33 & 6.37 & 6.43 & 6.34 & 6.43 & 6.38 & 6.40 \\
\hline 2 & 34 & 6.72 & 6.79 & 6.69 & 6.79 & 6.73 & 6.77 \\
\hline 2 & 35 & 7.06 & 7.13 & 7.04 & 7.14 & 7.07 & 7.12 \\
\hline 2 & 36 & 7.39 & 7.47 & 7.37 & 7.48 & 7.40 & 7.45 \\
\hline 2 & 37 & 7.70 & 7.78 & 7.68 & 7.79 & 7.71 & 7.77 \\
\hline 2 & 38 & 7.98 & 8.07 & 7.96 & 8.09 & 7.99 & 8.06 \\
\hline 2 & 39 & 8.22 & 8.31 & 8.20 & 8.34 & 8.24 & 8.32 \\
\hline 2 & 40 & 8.43 & 8.51 & 8.41 & 8.55 & 8.46 & 8.52 \\
\hline 2 & 41 & 8.60 & 8.67 & 8.59 & 8.71 & 8.64 & 8.68 \\
\hline 2 & 42 & 8.73 & 8.79 & 8.72 & 8.84 & 8.77 & 8.81 \\
\hline 2 & 43 & 8.82 & 8.88 & 8.81 & 8.94 & 8.87 & 8.90 \\
\hline 2 & 44 & 8.87 & 8.95 & 8.87 & 9.01 & 8.92 & 8.97 \\
\hline
\end{tabular}




\section{Figure captions}

Figure 1. Study area and the salinity stations

Figure 2. Comparison of measured and simulated water levels at Khosrowabad station $(n=0.022)$

Figure 3. Comparison of measured and simulated salinity profile for Ghosbeh station at 20:00, 6 February

Figure 4. Comparison measured and simulated salinity profile for Ghosbeh station at 15:30, 28 January

Figure 5. Tracer mass content within the estuary

Figure 6. Flushing time using Equations 5 (solid line) and 6 (dashed line)

Figure 7. Average salinity of the Arvand River estuary due to different inflow (a) $240 \mathrm{~m}^{3} / \mathrm{s}$, (b) $580 \mathrm{~m}^{3} / \mathrm{s}$, and (c) $1040 \mathrm{~m}^{3} / \mathrm{s}$

Figure 8. Flushing time of Arvand River estuary using fraction of freshwater method

Figure 9. Pulse residence time for different tidal amplitude

Figure 10. Estuarine residence time of Arvand River

Figure 11. Residence time of Arvand River for different release points and discharge rates 


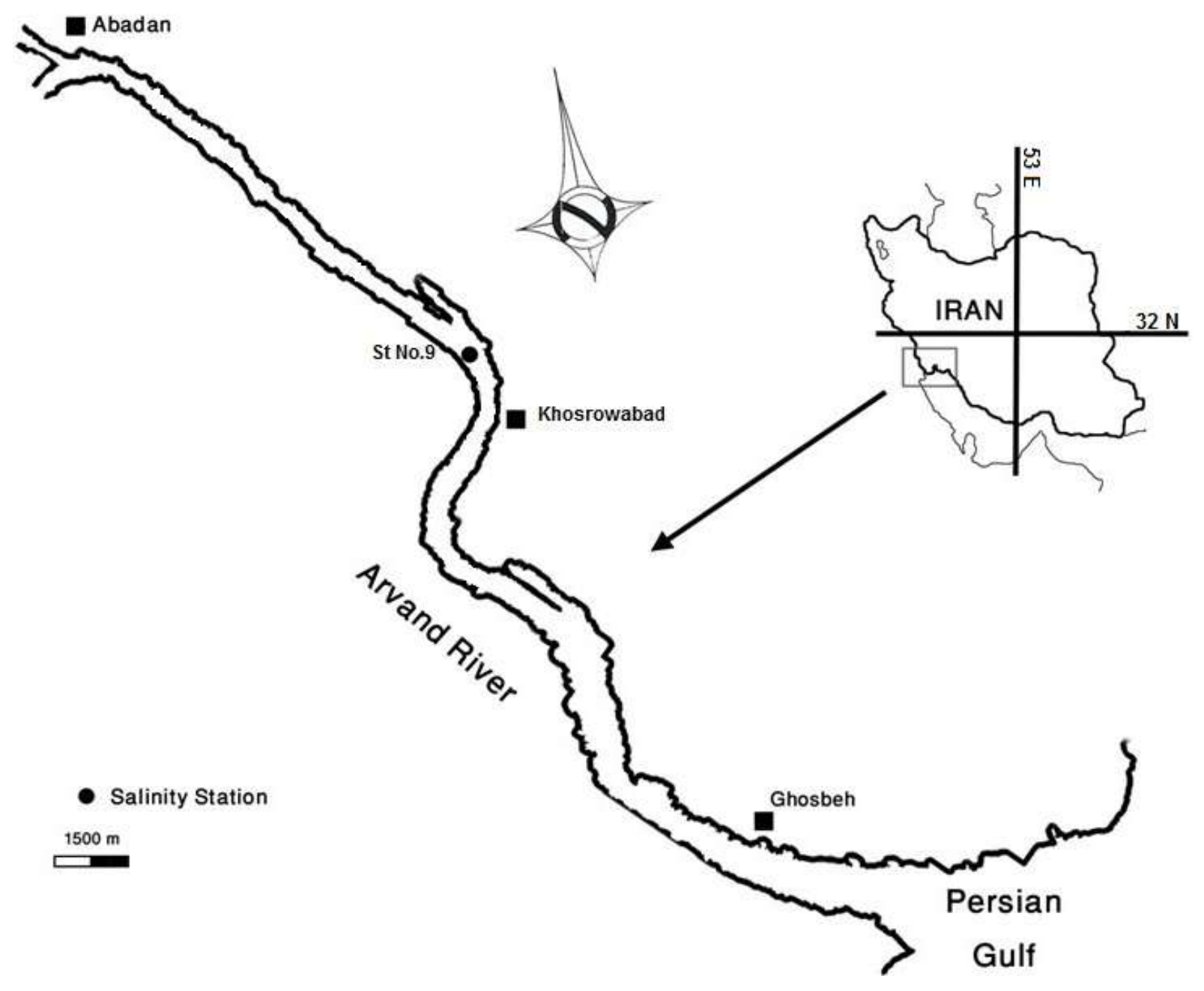

Figure 1. Study area and salinity measurement stations 


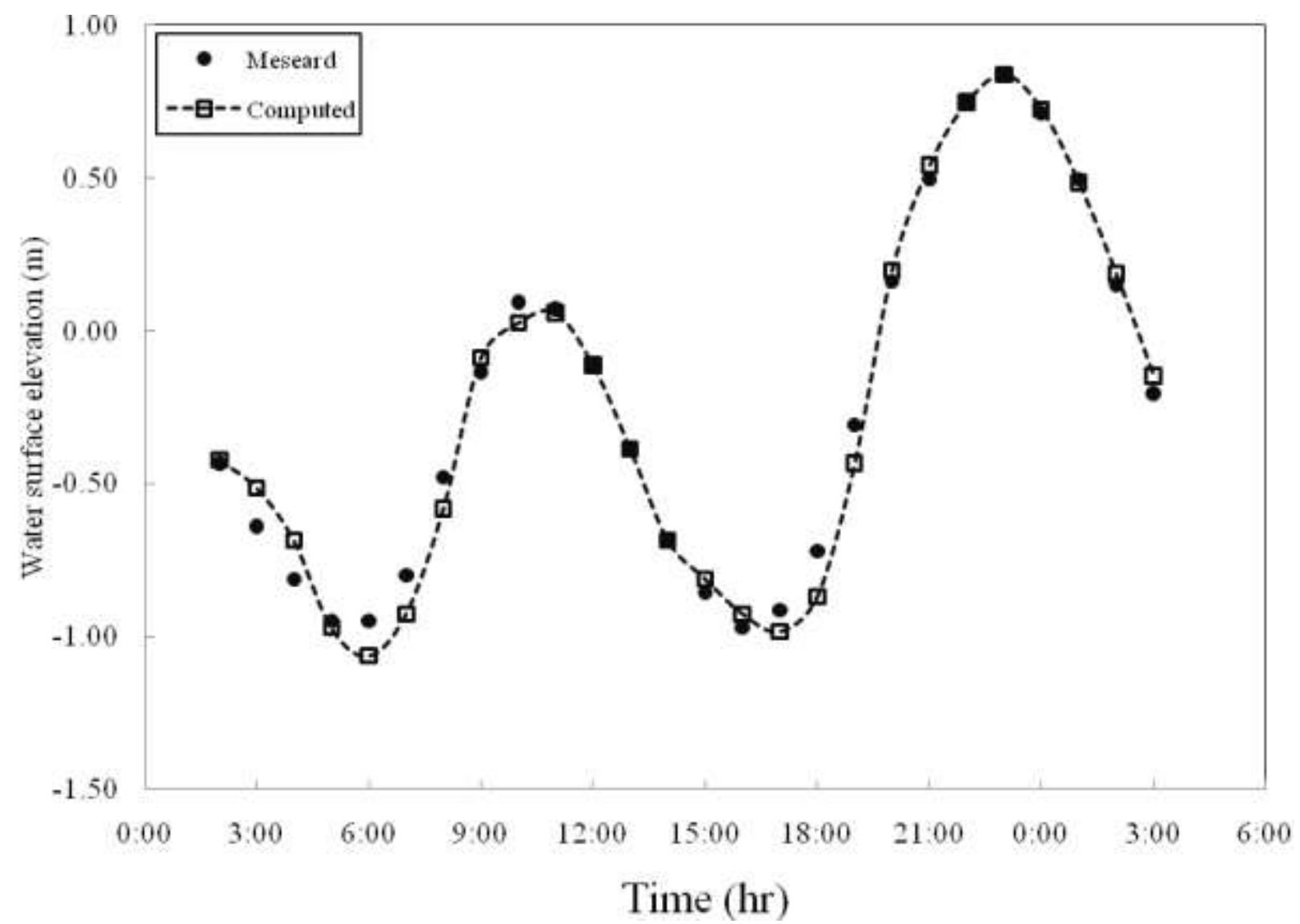

Figure 2. Comparison of measured and simulated water levels at Khosrowabad station $(n=0.022)$ 


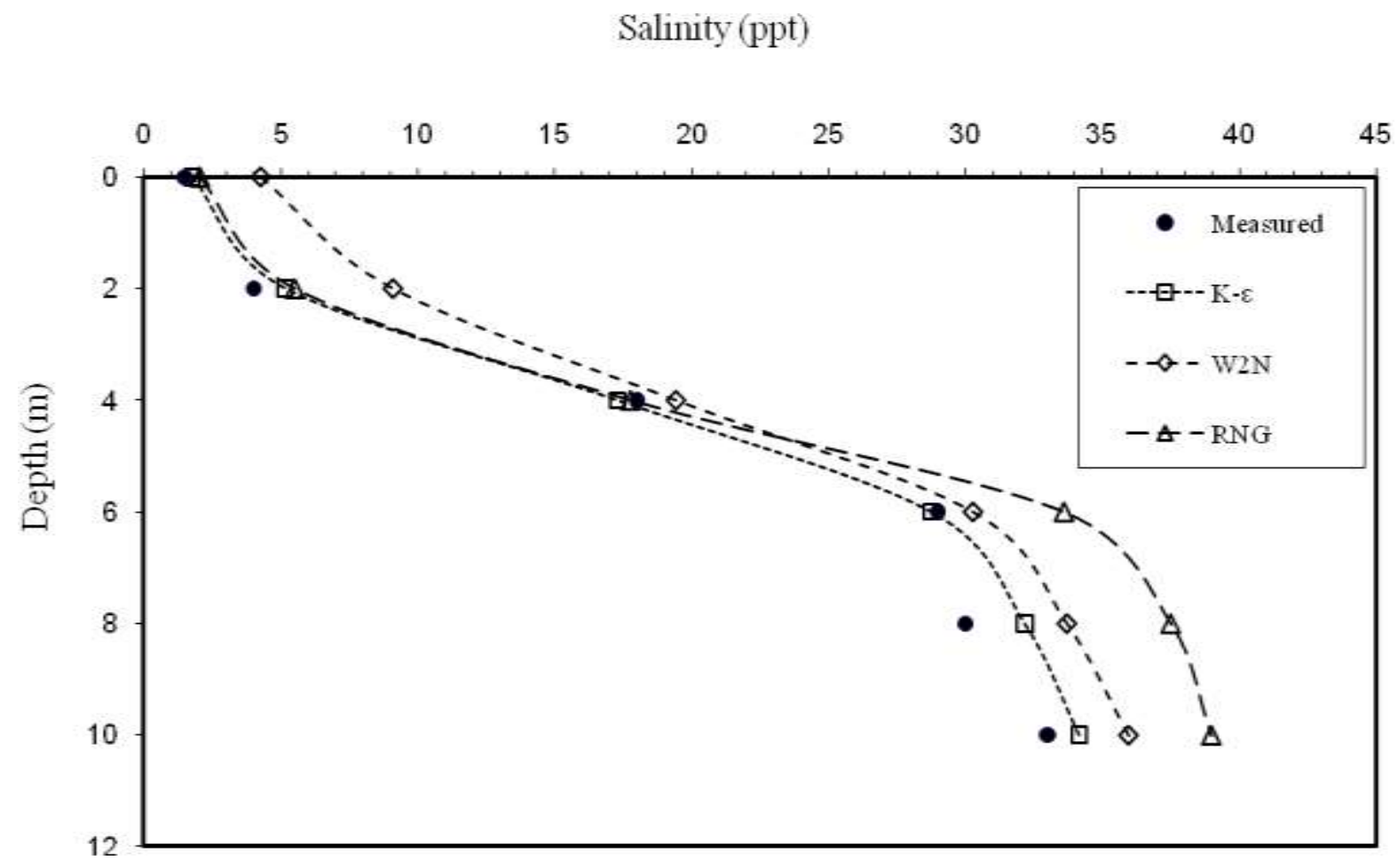

Figure 3. Comparison of measured and simulated salinity profile for Ghosbeh station at 20:00, 6 February 


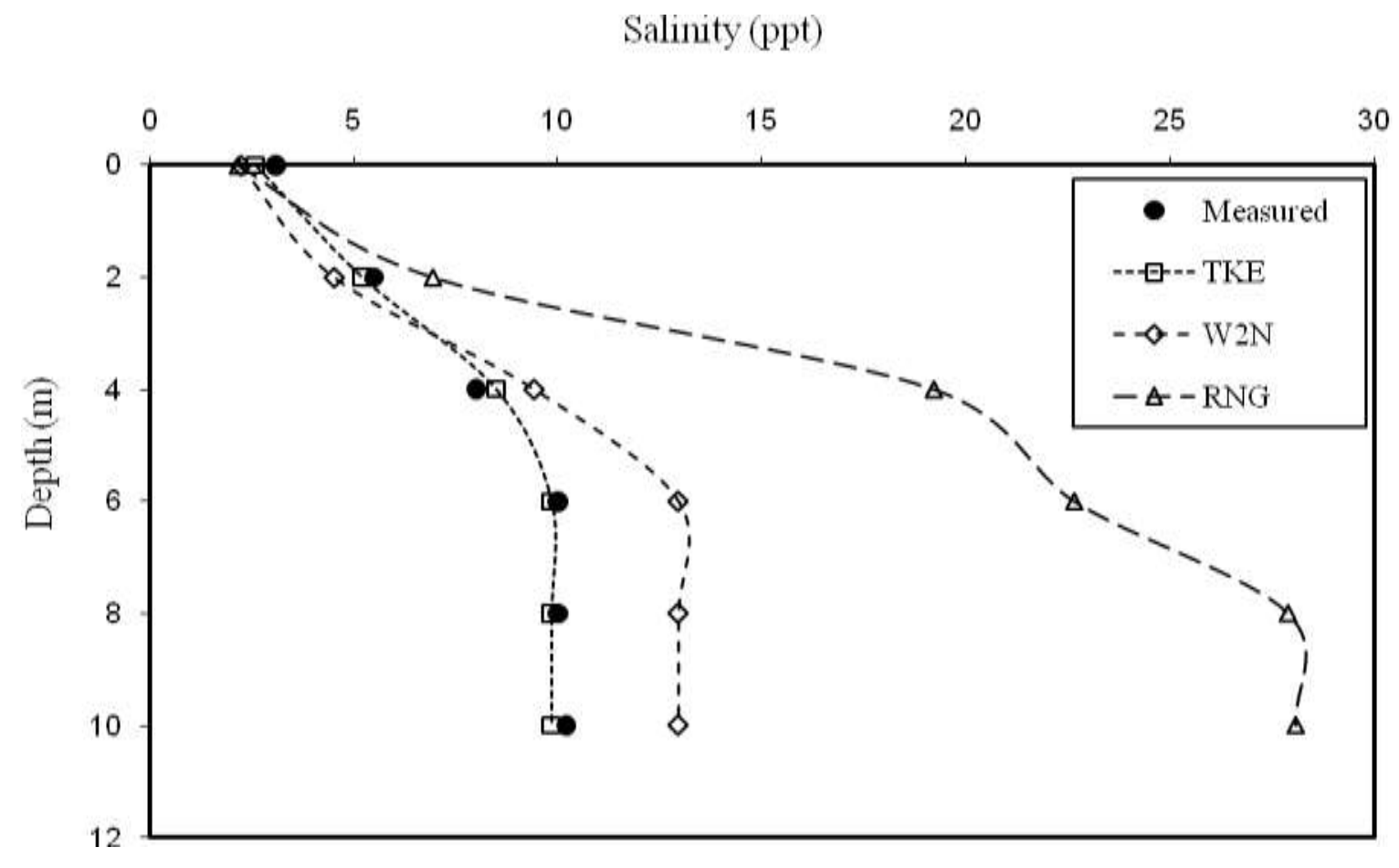

Figure 4. Comparison of measured and simulated salinity profile for Ghosbeh station at 15:30, 28 January 


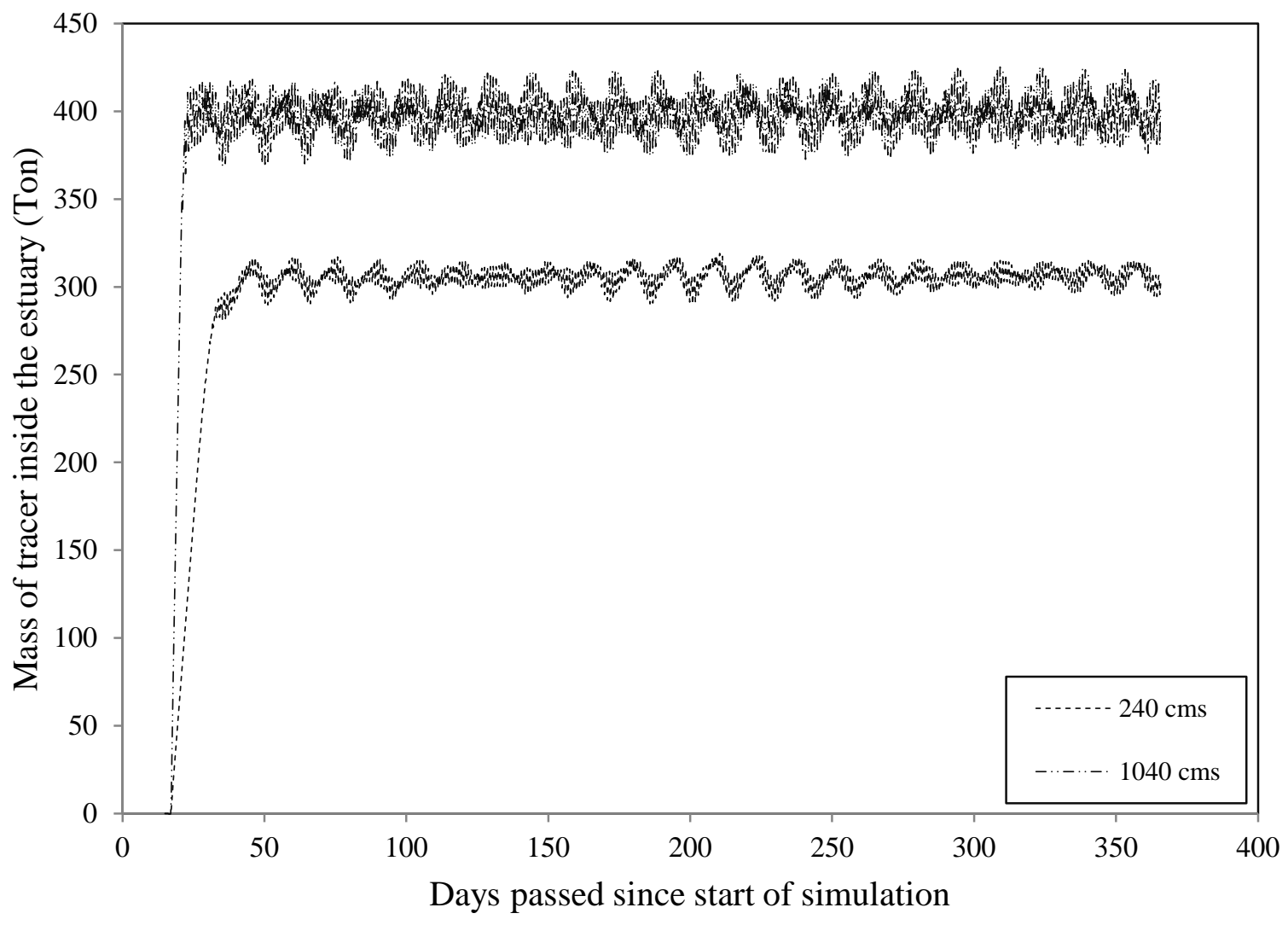

Figure 5. Tracer mass content within the estuary 


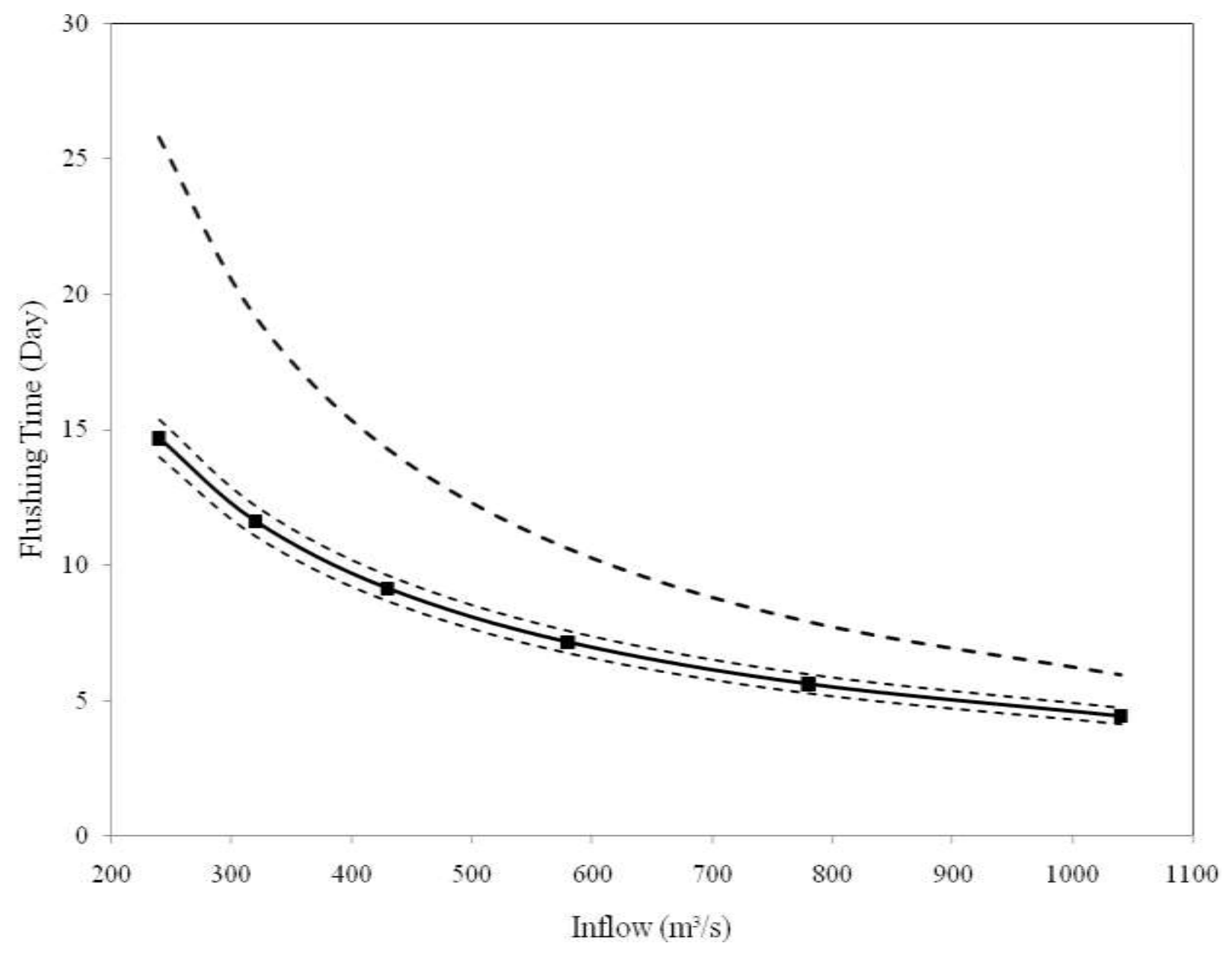

Figure 6. Flushing time using Equations 5 (solid line) and 6 (dashed line) 

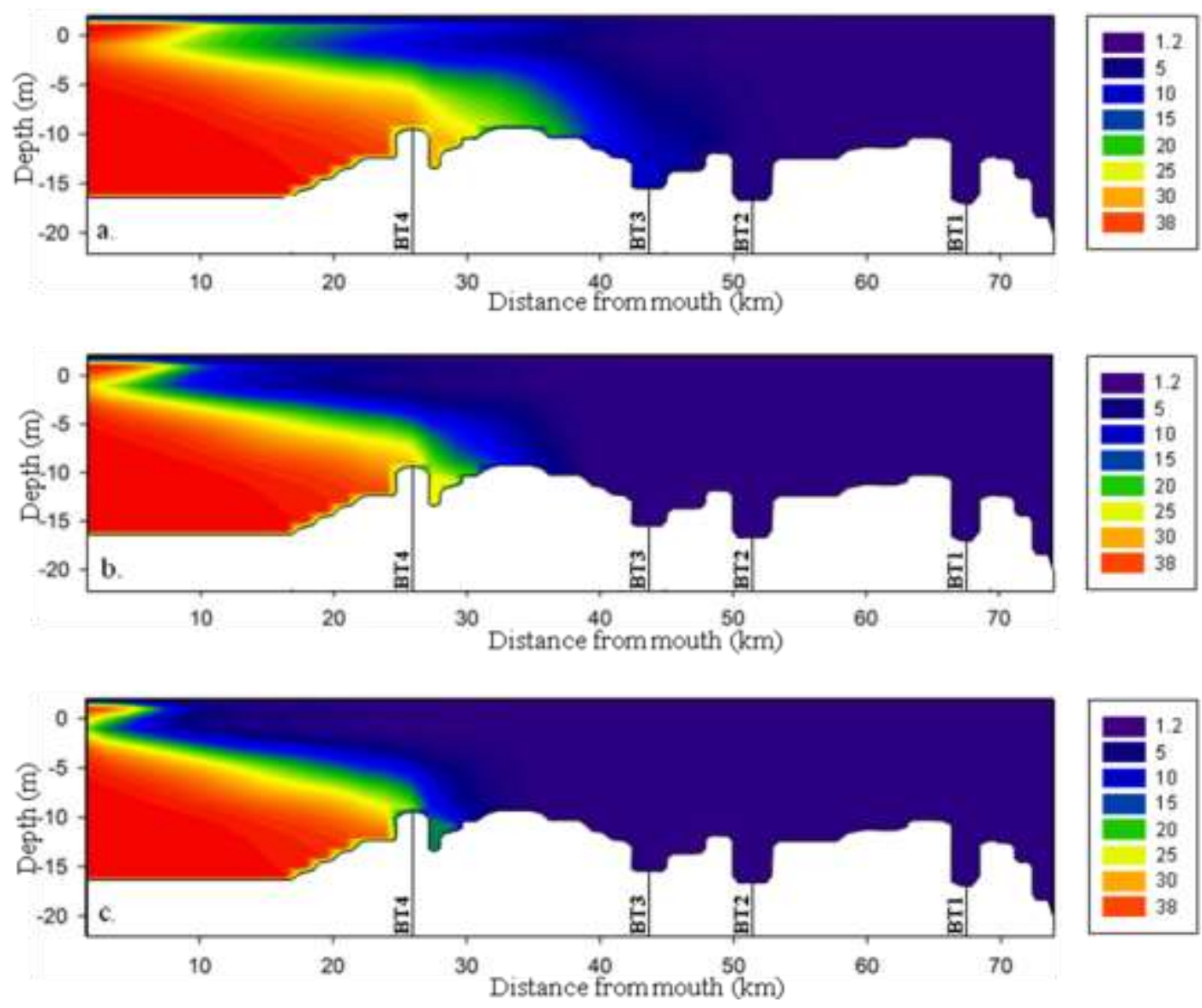

Figure 7. Average salinity of the Arvand River estuary due to different inflow (a) $240 \mathrm{~m}^{3} / \mathrm{s}$, (b) $580 \mathrm{~m}^{3} / \mathrm{s}$, and (c) $1040 \mathrm{~m}^{3} / \mathrm{s}$ 


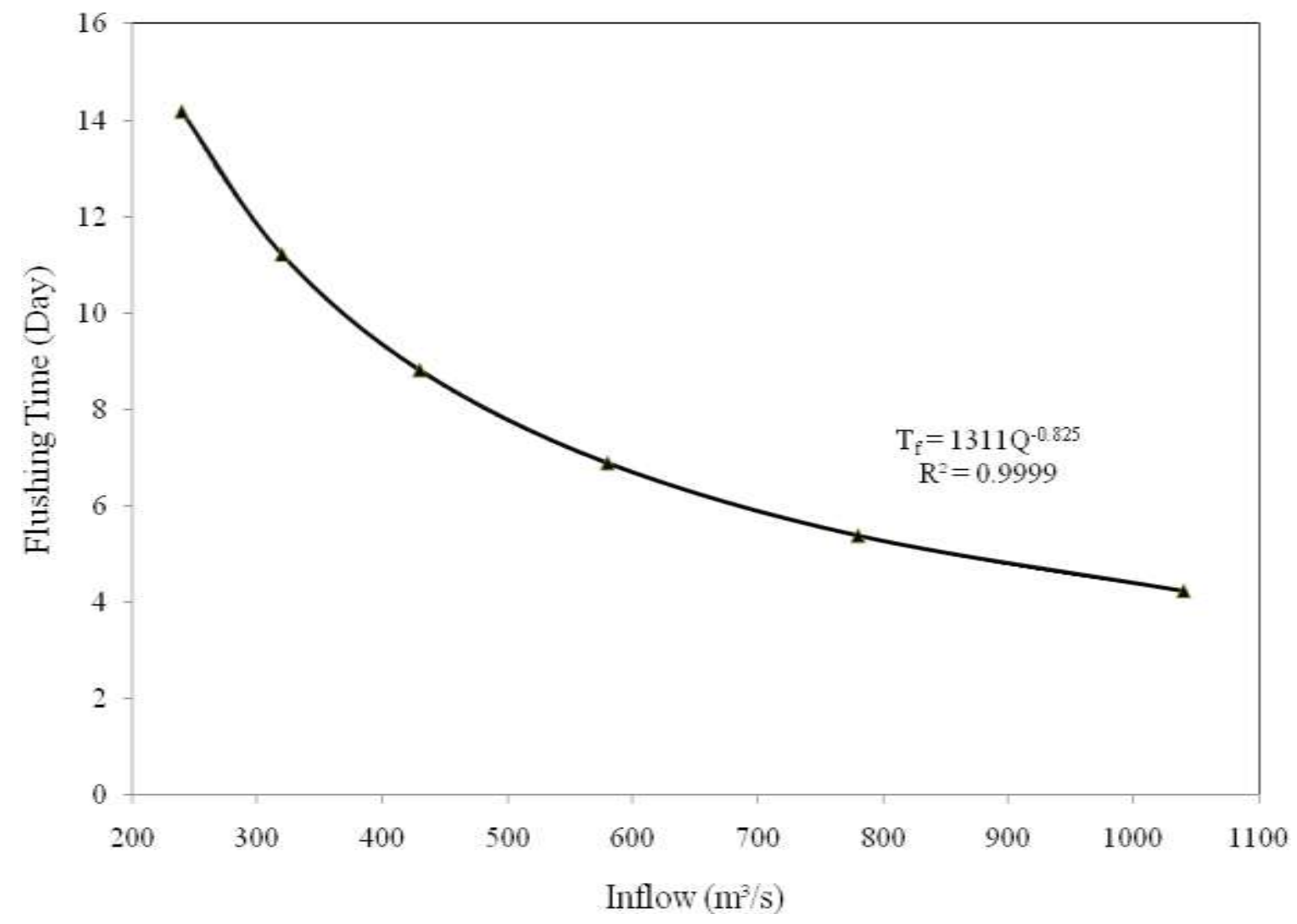

Figure 8. Flushing time of the Arvand River estuary using fraction of freshwater method 


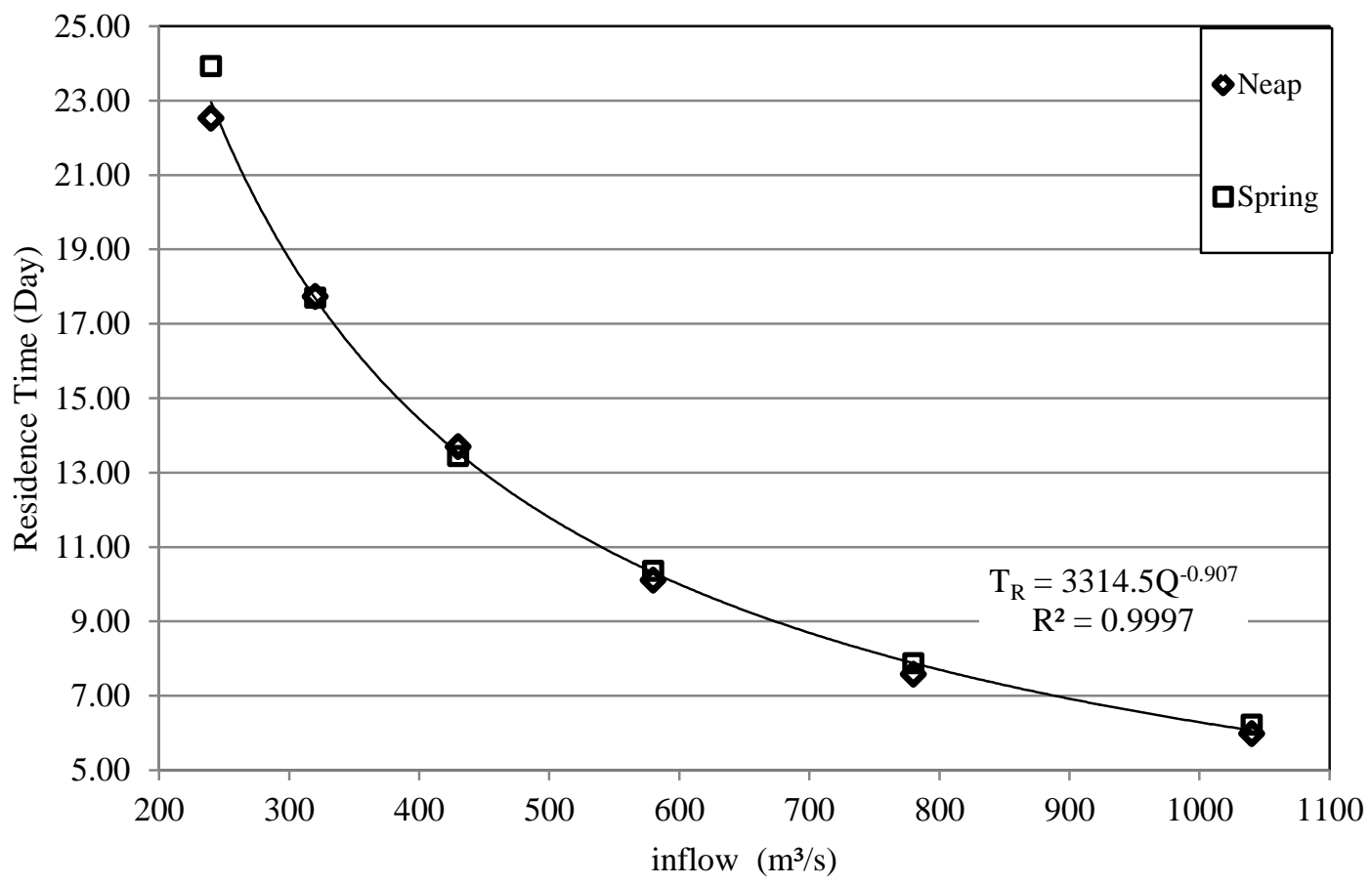

Figure 9. Pulse residence time for different tidal amplitude 


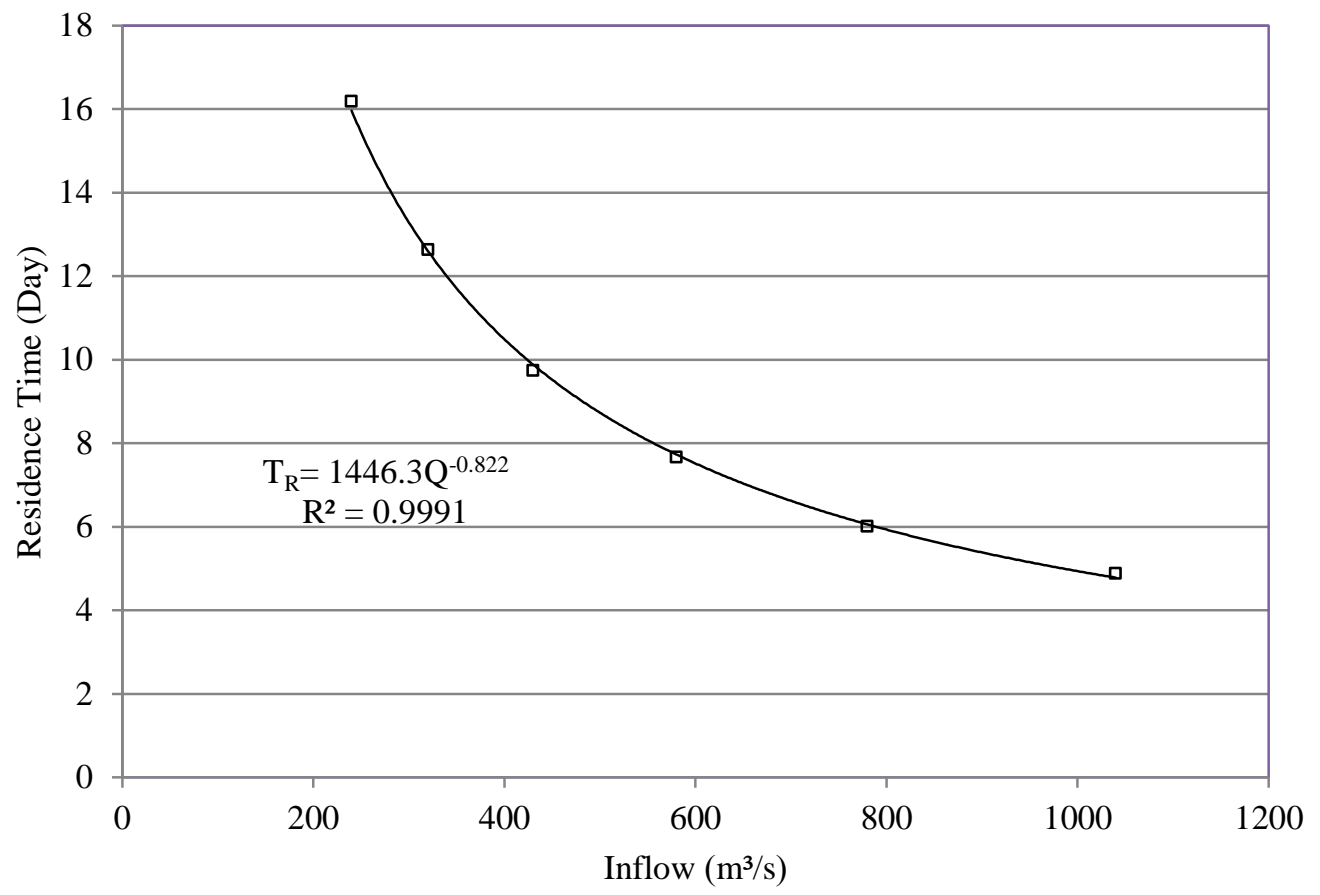

Figure 10. Estuarine residence time of Arvand River 


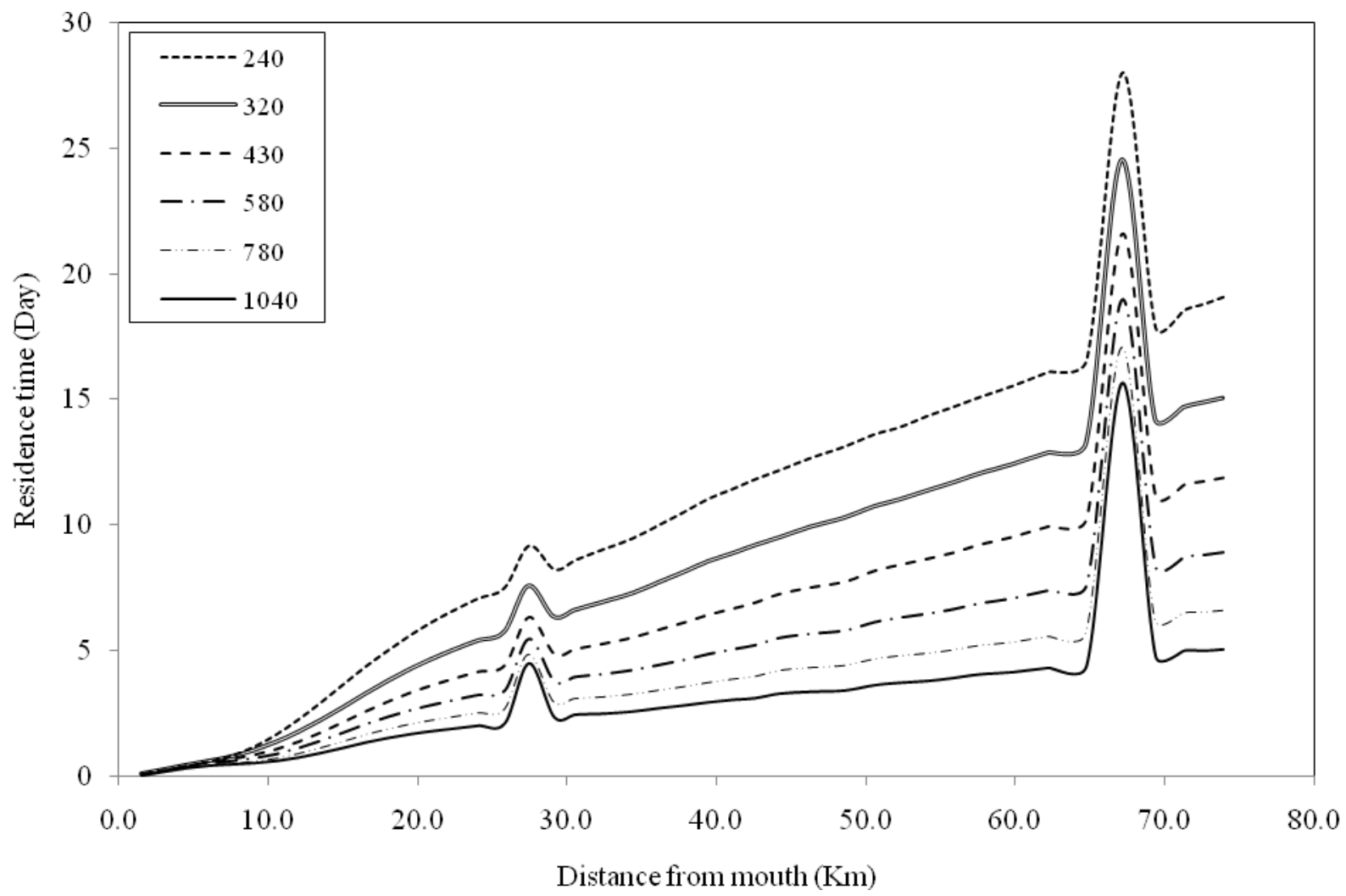

Figure 11. Residence time of Arvand River for different release points and discharge rates 